\title{
Analysis of Greenhouse Gas Emissions for Carbonated Soft Drinks Using LCA Methodology
}

\author{
Jongsek Kim ${ }^{1,+\oplus} \cdot$ Noh-Hyun $\operatorname{Lim}^{2 \oplus} \cdot$ Yoonmi Shin $^{1 \oplus} \cdot$ Kyungwook Park $^{1 \oplus} \cdot$ Ihn Sup Han $^{1 \oplus}$ \\ ${ }^{1}$ Department of Environmental Engineering, University of Seoul \\ ${ }^{2}$ Institute of Global Sustainability Certificate (IGSC)
}

(Received October 12, 2020; Revised December 4, 2020; Accepted December 8, 2020)

Objectives: In accordance with the concern of global warming problem, many companies in Korea are striving to reduce greenhouse gas emissions in accordance with consumer awareness. Many studies have been reported for various products; however it is difficult to find carbonated soft drinks in Korea. The purpose of this study is to the impact of the greenhouse gas emissions, especially carbonated soft drinks in Korea.

Methods: Calculation method of the greenhouse gas emissions followed "Guidelines for Carbon Footprint of Products" used in Korean Carbon Footprint Labeling. It was developed based on international standards such as ISO 14040 series. Life cycle of carbonated soft drinks was considered as a pre-manufacturing stage, manufacturing stage, distribution and disposal stage. Use stage of the product was excluded.

Results and Discussion: This study shows that the package types and amounts for pre-manufacturing, manufacturing and disposal steps of carbonated soft drinks (the unit contents: $500 \mathrm{~mL} / \mathrm{unit}, 1.5 \mathrm{~L} / \mathrm{unit}$ ), and also shows the results of greenhouse gas emissions. From the results, the pre-manufacturing stage of PET bottle manufacturing is the first contributor that occupy above $60 \%$ of greenhouse gas emissions. For reducing carbon emissions, low carbon manufacturing techniques for PET bottle are important. Sensitivity analysis was performed for PET bottle manufacturing, cap manufacturing and waste plastic disposal including site data and assumptions made. The sensitivity of each item was less than $7 \%$.

Conclusions: In conclusion, this study shows that the pre-manufacturing step of PET bottle and cap production have very significant impact on the greenhouse gas emissions. Therefore lightweight packages and usage of recycled plastics would be main techniques for reducing greenhouse gas emissions of carbonated soft drinks. From this study, the increment of product's carbon footprint certification would be used as an effective policy instrument for achieving reduction goals of Korea Government. And also it could be used to spread the culture of reducing greenhouse gas emissions.

Keywords: Carbonated Soft Drinks, LCA, Carbon Footprint, Sensitivity Analysis 


\title{
연구논문
}

\section{전과정평가 기법을 활용한 탄산음료의 탄소배출량 평가}

\author{
김종석 ${ }^{1+\odot} \cdot$ 임노현 $^{2 \odot} \cdot$ 신윤미 $^{1 \odot} \cdot$ 박경욱 $^{1 \odot} \cdot$ 한인섭 $^{1 \odot}$ \\ ${ }^{1}$ 서울시립대학교 환경공학부 \\ 2국제지속가능인증원
}

목적 : 지구온난화로 인한 기상이변에 따른 소비자 인식이 증가하면서 기업들은 온실가스 배출을 줄이기 위해 노력 하고 있다. 다양한 제품에 대한 많은 연구가 보고되고 있지만 우리나라에서 탄산음료 제품에 대한 온실가스 배출 과 관련한 연구는 찾아보기가 어렵다. 따라서 본 연구의 목적은 대표적인 국내 탄산음료 제품의 온실가스 배출량 및 영향을 분석하고자 한다.

방법: 본 연구에서 사용한 온실가스 배출량 산정 방법은 환경부의 환경성적표지 작성지침 방법론에 따라 산정했 고, 이는 ISO 14040 등의 국제표준을 기반으로 개발되었다. 탄산음료에 대한 전과정평가 단계는 제조 전단계, 제 조 단계, 유통 및 폐기 단계에 대하여 고려되었으며 사용단계는 환경부 방법론에 따라 제외하였다.

결과 및 토의: 본 연구대상인 탄산음료 $500 \mathrm{~mL}, 1.5 \mathrm{~L}$ 의 전과정평가를 통해 도출된 제조 전단계, 제조 및 폐기단계 에서의 온실가스 배출량 결과를 분석한 결과, 전체 온실가스 배출량의 $60 \%$ 이상이 제조 전단계인 PET병 제조공정 에서 배출되는 것으로 조사되었다. 따라서 탄산음료의 온실가스 배출량을 줄이기 위해서는 제조 전단계에 해당되 는 PET병 제조에 대한 온실가스 배출량을 줄이도록 노력해야 한다. 연구에 활용된 주요 데이터 및 가정에 대해 민 감도 분석을 수행하였고, PET병 및 마개 제조단계에서 재활용 플라스틱 적용 및 최종 폐기단계에서 재활용율 $10 \%$ 향상을 가정했는데 민감도는 $7 \%$ 미만으로 도출되어 연구 결과에 대한 신뢰도는 높다고 판단된다.

결론 : 본 연구결과를 토대로 하여 탄산음료의 온실가스 배출량을 저감하기 위해서는 플라스틱 포장재 경량화 및 포장재 원료로 재활용 플라스틱과 신재와 혼합하여 PET병 포장재를 제조하는 것이 온실가스 배출량을 줄이는 주 요 방안이 됨을 확인하였다. 또한 본 연구와 같이 제품 온실가스 배출량 조사 및 인증은 산업계 온실가스 감축 및 저탄소 소비자 문화 확대에도 기여할 것으로 사료된다.

주제어: 탄산음료, 전과정평가, 탄소발자국, 민감도 분석

\section{1. 서론}

기후변화에 따른 기상 이변이 전 세계적인 증가로 인한 피해 가 증가하고 있으며 이로 인한 자연재해 역시 증가하면서 인 류의 건강과 생태계의 지속성에 중대한 영향을 미치는 것으로 보고되고 있다. 기후변화의 심각한 피해에 대한 전 세계적인 우려는 국제사회에서 기후변화의 주원인으로 지목되는 온실 가스 감축의 필요성 인식과 이에 대한 강력한 실천이 필요하 다는데 전 세계적 동의가 이루어지게 되었다. 이와 관련해서 2016년 유엔본부에서는 전 세계 모든 국가가 참여하는 신기후 체계의 근간이 되는 파리협정에 우리나라를 포함한 세계 각국 이 공식 서명하였다. 이는 선진국 주도의 교토의정서 체제를 극복하기 위한 것으로 선진국과 개발도상국 모두가 참여하며 각국이 온실가스 감축목표를 스스로 결정하여 감축을 이행하
는 방식을 채택하였다. ${ }^{1)}$

국제사회의 노력의 발맞추어 우리나라는 국가 온실가스 배 출량을 2030 년의 배출전망치 대비 $37 \%$ 를 감축하는 목표를 채택하였다. ${ }^{2)}$ 이러한 목표를 달성하기 위해서는 각 주체별로 온실가스 감축을 위한 각 주체별의 적극적인 노력이 필요하 다. 즉, 정부 주도의 온실가스 감축 노력만으로는 배출전망치 대비 $37 \%$ 수준을 줄이는 것에는 한계가 있기에 기업과 소비자 들의 인식 재고 및 이에 대한 실천이 반드시 요구된다. 이와 관련하여 저탄소기술 및 문화 확대를 위해 환경부에서는 환경 성적표지 제도를 운영하여 기업에서 제공하는 제품 및 서비스 의 환경영향 및 온실가스 배출량에 대한 정보를 자발적으로 소개하고 있다. 이러한 환경성적표지 제도는 제품 및 서비스 의 환경성 제고를 위해 전과정에 대한 환경영향을 평가하는 제도이며 2020년 8월말 기준으로 446개 기업의 3,948개 제품 
이 인증받았다. ${ }^{3)}$ 이를 통해 환경을 고려한 제품이 시장을 주도 하도록 유도하여 지속적으로 환경개선에 대한 투자와 관심이 이루어지도록 하고 있다. 이에 따라 기업들은 제품의 환경성 을 개선하고 온실가스 발생량이 저감되는 친환경 제품 개발에 대한 노력을 하고 있고 이를 마케팅에 활용하여 소비자들에게 친환경 제품 선택을 유도하고 있다. 환경성적표지 제도는 전 과정평가 기법을 활용하여 제품 및 서비스의 전과정에 대한 환경영향을 평가하는데, 이러한 전과정평가와 관련해서 국내 에서도 다양한 분야의 연구가 진행되었다. Heo 외(2017)는 전과정평가 기법을 적용하여 휴대폰 충전기 제조시 재생 플라 스틱을 사용할 경우의 환경영향을 신재 플라스틱의 경우와 비교하여 연구하였다. 그 결과 충전기의 사용단계에서의 환경 영향이 자원고갈에서 $94.4 \%$, 지구온난화에서 $70 \%$ 로 가장 큰 환경영향을 미치는 것으로 확인되었다. ${ }^{4)} \mathrm{Kwak}$ 외(2016)는 전 과정평가 기법을 이용해 대표적인 렌탈 제품인 공기청정기 신품과 재제조 제품의 환경성평가를 비교 연구하였다. 공기청 정기 신품 대비 재제조 제품의 환경적 개선 효과를 정량적으 로 분석한 결과 공기청정기 1 대 재제조 시의 환경영향이 신품 대비 약 $20.7 \%$ 감소되고, 공기청정기의 원료 추출 단계에서 자원고갈 및 지구온난화에 대한 환경개선 효과가 가장 높은 것으로 확인하였다. ${ }^{5)} \mathrm{Kim}$ 외(2020)는 교통수단별 미세먼지 발자국을 산정하는 연구를 전과정평가 기법을 활용하여 수행 하였다. 연구결과 트럭운송이 철도 및 해상교통에 비해 미세 먼지 발자국이 높게 나타났음을 확인하였고, 미세먼지 형성에 기여하는 가스상물질들은 육상수송에 $59 \%$, 철도수송에 $80 \%$, 해상수송에는 $61 \%$ 의 기여도를 가지는 것을 확인했다. ${ }^{6}$

음료제품은 일반 소비자들이 쉽게 접하고 있는 대표적인 소비재 제품이다. 국내 음료시장은 탄산음료, 과채음료, 커피 및 기타 음료로 구분되고 있다. 식품공전 기준 음료류 생산규 모를 살펴보면 2014년도 생산량은 4,756,285톤에서 2018년 $5,404,607$ 톤으로 약 $12 \%$ 증가했으며, 매출액도 동일기간 6 조 1,306 억원에서 6 조 4,779 억원으로 약 $5.4 \%$ 증가하였다. 음료 품목별로 2018년 생산량을 세분하면 탄산음료가 전체 음료의 $35 \%$ 인 186.7 만톤을 생산하여 가장 큰 비중을 차지하고 있다. 그 외 커피 82.0만톤/년, 과채음료류 61.7만톤/년, 다류 46.4만 톤/년, 두유류 30.9만톤/년이 생산되었다. 탄산음료류의 생산 량의 증가 원인은 건강에 대해 관심이 높아진 소비자 트렌드 에 따라 설탕이나 열량을 줄인 제품이 출시가 증가되면서 소 비자의 호응을 얻은 것으로 보이며, 최근 간편식과 배달음식 이 성장하면서 함께 음용하는 제품으로 탄산음료 소비도 함께 증가하고 있는 추세이기 때문이다. ${ }^{7)}$

이러한 국내 음료시장은 꾸준하게 성장하고 있으나 음료 제조공정 및 원부자재 사용에 따른 환경 부하를 정량적으로 산정하거나 이에 대한 환경 개선 효과를 파악한 연구는 많지 않다. 특히 국내에서 제조 유통되는 음료제품에 대한 전과정 에서의 온실가스 배출에 대한 국내 연구 사례는 미흡한 수준
이지만, 해외에서는 음료 및 주류제품에 대한 전과정평가를 활용한 연구가 활발하게 수행되었다. Pasqualino 외(2011)는 전과정평가 기법을 활용하여 스페인에서 생산되는 과일주스, 생수, 맥주와 같은 음료 및 주류제품의 알루미늄, 종이팩, 유리 및 플라스틱 재질 포장재의 폐기방법에 따른 환경성평가를 연구하였다. ${ }^{8)}$ Amienyo 외(2013)는 영국에서 제조 및 판매되 는 탄산음료를 대상으로 전과정평가를 통한 환경영향을 연구 하였다. 연구결과 탄산음료의 포장재의 환경영향 기여도가 $59 \sim 7 \%$ 로 가장 높았으며, 유통 및 판매과정에서 소매점의 탄산음료 냉장시설 가동에 이용되는 에너지 사용에 따른 지구 온난화 지수가 $33 \%$ 이상으로 조사되었다. ${ }^{9}$

따라서 본 연구도 국내에서 제조 및 유통되는 음료 중에서 생산비중이 가장 큰 탄산음료를 대상으로 선정하여 전과정평 가 기법을 통해 탄산음료의 온실가스 배출에 대한 평가를 실 시하고자 한다. 즉, 탄산음료의 원료물질과 포장재의 제조, 탄산음료 생산, 폐기의 전과정 동안의 온실가스 배출량을 정 량적으로 평가하겠으며, 이를 통해 주요 온실가스 배출 공정 을 규명하여 적용 가능한 개선 대안을 도출하여 개선에 도움 이 될 수 있도록 하는데 연구목적이 있다.

\section{2. 자료 및 연구방법}

본 연구는 탄산음료의 온실가스 배출량 산정을 위해 우리나 라 환경부의 환경성적표지 제도의 인증 공통지침에 근거하였 다. 환경성적표지 공통지침에서 탄산음료는 일반제품의 비내 구재에 해당되어 제품의 사용단계의 환경영향을 고려하지 않 고 있다. 그리고 비내구재의 정의를 식료품 및 화장지 등과 같이 장기사용을 목적으로 하지 않는 재화로 설명하고 있다. ${ }^{10)}$ 따라서 본 연구에서의 시스템 경계는 제조 전단계, 제조단계, 폐기단계를 포함했지만, 사용단계는 조사 대상에서 반영하지 않았다. 그러나 해외 연구논문을 보면 탄산음료에 대해 사용 단계를 반영한 사례도 보고되고 있다. 영국의 사례를 예를 든다면, Amienyo 외(2013)는 영국에서 제조되는 탄산음료에 대한 전과정평가에서 사용단계로 탄산음료 판매를 위해 이 용하는 냉장고 사용에 따른 에너지 사용을 조사범위에 포함 하였다. 그러나 본 연구에서는 우리나라 환경부의 방법론을 적용하여 사용단계의 온실가스 배출량 산정과정은 포함하지 않았다. ${ }^{9)}$

\section{1. 연구 수행 범위}

\subsection{1. 제품 선정}

음료는 다양한 포장재를 사용하고 있으며, 전 세계 음료 제 품에서의 플라스틱 포장재는 2015년 매출액 기준으로 약 370 억 달러를 차지하였으나, 이에 비해 캔과 유리병은 각각 120 억 달러 및 54억 달러에 그쳤다. ${ }^{11)}$ 따라서 본 연구에서는 전세계 적으로 가장 많이 사용하는 플라스틱 포장재인 PET병 제품의 
Table 1. Product specification of carbonated soft drinks.

\begin{tabular}{|c|c|c|c|}
\hline \multirow{2}{*}{\multicolumn{2}{|c|}{$\begin{array}{c}\text { Category } \\
\text { Product (model) }\end{array}$}} & \multicolumn{2}{|c|}{ Target product of LCA study } \\
\hline & & Carbonated soft drink (PET $500 \mathrm{~mL}$ ) & Carbonated soft drink (PET $1.5 \mathrm{~L}$ ) \\
\hline \multirow{7}{*}{ Weight (g/unit) } & Product & 513.80 & $1,541.39$ \\
\hline & Container & 23.83 & 42.84 \\
\hline & Stopper & 2.30 & 2.30 \\
\hline & Label, Glue & 0.79 & 1.28 \\
\hline & Secondary package (Paper) & 2.49 & 4.86 \\
\hline & Secondary package (Plastic film) & 1.98 & 3.05 \\
\hline & Total & 545.18 & $1,595.73$ \\
\hline
\end{tabular}

Table 2. Function, functional unit of carbonated soft drinks.

\begin{tabular}{|c|c|}
\hline Category & Description \\
\hline Function & Carbonated soft drinks \\
\hline Functional unit & $\begin{array}{l}\text { A carbonated soft drink A carbonated soft drink } \\
\text { PET } 500 \mathrm{~mL}, 1 \text { unit } \\
\text { PET } 1.5 \mathrm{~L}, 1 \text { unit }\end{array}$ \\
\hline
\end{tabular}

탄산음료를 연구대상으로 선정하였다. 대표적인 플라스틱 포 장재인 $\mathrm{PET}$ 병 제품 중 소비자 선호도가 높은 $500 \mathrm{~mL}$ 와 1.5 $\mathrm{L}$ 용량의 탄산음료 제품을 선정하여, 원료 및 포장재 및 기타 원부자재의 중량을 Table 1에 자세히 기술하였다.

환경성적표지 작성지침에 따라 기능(function) 및 기능단위 (functional unit)는 시장에 출시되는 제품의 단위가 명확한 경 우, 제품 1 개 등 제품 판매 단위를 기준으로 설정하도록 한 다. ${ }^{11)}$ 따라서 본 연구에서는 Table2와 같이 탄산음료 $500 \mathrm{~mL}$ 와 탄산음료 $1.5 \mathrm{~L}$ 의 전과정평가를 위한 기능(function) 및 기 능단위(functional unit)에 대해 기술하였다.

\subsection{2. 시스템 경계 설정}

본 연구에서는 탄산음료 $500 \mathrm{~mL}$ 와 $1.5 \mathrm{~L} \mathrm{PET병} \mathrm{제품에}$ 대해서 제조 전단계에서는 설탕시럽 원재료와 PET병과 병마 개 제조 및 수송을 고려하였다. 제조단계에서는 제조사업장에 서의 탄산음료 생산 및 제조된 제품의 제조사업장에서 물류센 터로의 수송을 고려하였다. 그러나 사용단계는 환경부 방법론 에 따라 제외하였으며, 폐기단계에서는 포장재의 매립, 소각, 재활용을 고려하여 온실가스 배출량을 산정하였다. 원재료 및 포장재는 환경성적표지 인증 지침에 따라 누적 질량기여도 $95 \%$ 로 이상의 원재료 및 포장재에 대한 사업장 현장데이터를 수집하였다. 따라서 본 연구에서 설탕시럽 원재료와 PET병과 병마개는 누적 질량기여도 $95 \%$ 에 포함되었으나, 제품에 주입 되는 탄산가스는 누적 질량기여도에 포함되지 않아 조사대상 에서 제외하였다. ${ }^{10)}$

탄산음료 제품 제조공정은 Fig. 1과 같이 현장데이터를 수집 하였으며, 제품 생산과 직접적인 연관이 없는 소모품, 공장 내부 수송에 의한 에너지 사용 등은 데이터 수집범위에서 제 외되었다. 또한 소비자가 제품을 사용 후 폐기하는 단계는

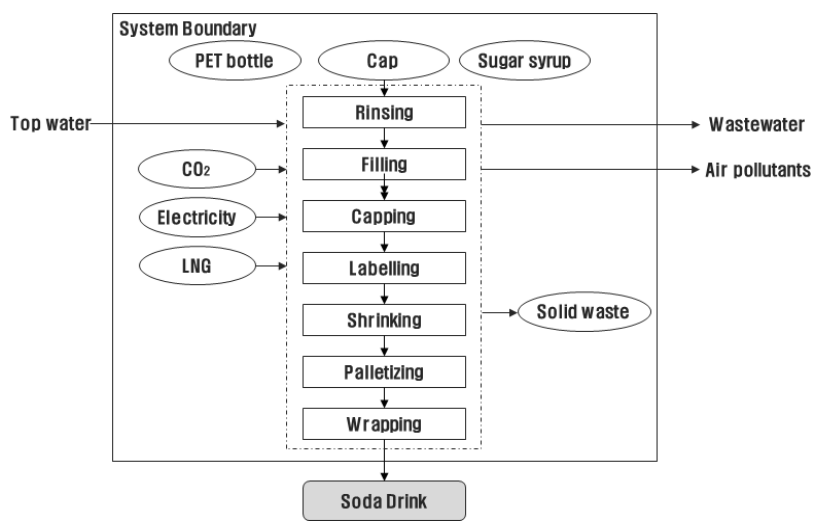

Fig. 1. Process diagram of carbonated soft drinks.

환경부 방법론에 따른 폐기 시나리오에 따라 매립, 소각, 재활 용 비율을 적용하였다. ${ }^{10)}$

\section{2. 온실가스 배출량 산정 방법}

탄산음료의 온실가스 배출량을 산정하기 위해서 투입 및 산출물질에 대한 개별 배출계수는 환경성적표지 인증 지침에 따라 현장데이터를 우선적으로 수집하였으며, 현장데이터가 없는 경우에는 해당 국가의 LCI DB를 활용하였고 세부사항은 Table3과 같다. 온실가스 산정은 원부자재 투입량에 대해 각 각의 배출계수를 곱하여 계산하였고 각 투입물의 배출량 값의 총합을 통해 총 배출량을 산정하였고, 이를 $\mathrm{kg}$ 당 이산화탄소 상당가로 환산하여 산정하였다.

\section{3. 결과 및 고찰}

\section{1. 탄산음료 $500 \mathrm{~mL}$, 탄산음료 $1.5 \mathrm{~L}$ 의 온실가스 배출량 산정결과}

탄산음료의 온실가스 배출량 산정을 위해서는 데이터 수집 과정읕 통해 온실가스 배출계수를 연결하여 산정하였다. 데이 터는 품질적인 측면에서 현장에서 조사된 데이터의 신뢰도가 가장 높지만, 현장 데이터 수집이 가능하지 않는 경우에는 계산 데이터 또는 추정 데이터 순서대로 신뢰도를 평가하고 있다. 환경부 환경성적표지 작성지침 방법론에는 제품 원료물 
Table 3. LCl database of carbonated soft drinks.

\begin{tabular}{|c|c|c|c|c|}
\hline \multirow{2}{*}{ Phase } & \multirow{2}{*}{ Material name } & \multicolumn{3}{|c|}{ LCl database } \\
\hline & & Source and arunit & Emission factor & Unit \\
\hline \multirow{15}{*}{ Pre-manufacturing } & Raw sugar & Ecoinvent & $1.86 \mathrm{E}-01$ & $\mathrm{kgCO}_{2 \mathrm{e}} / \mathrm{kg}$ \\
\hline & Top water & \multirow{14}{*}{$\begin{array}{l}\text { National LCI DB } \\
\quad \text { (Korea) }\end{array}$} & $3.32 \mathrm{E}-04$ & $\mathrm{kgCO}_{2 \mathrm{e}} / \mathrm{kg}$ \\
\hline & Slaked lime & & $5.28 \mathrm{E}-01$ & $\mathrm{kgCO}_{2 \mathrm{e}} / \mathrm{kg}$ \\
\hline & LNG-indirect & & $5.95 \mathrm{E}-01$ & $\mathrm{kgCO}_{2 \mathrm{e}} / \mathrm{kg}$ \\
\hline & LNG-direct & & $2.21 \mathrm{E}+00$ & $\mathrm{kgCO} \mathrm{e}_{2} / \mathrm{Nm}^{3}$ \\
\hline & Electricity & & 4.95E-01 & $\mathrm{kgCO}_{2 \mathrm{e}} / \mathrm{kWh}$ \\
\hline & Waste inorganic sludge & & $2.49 \mathrm{E}-01$ & $\mathrm{kgCO}_{2 \mathrm{e}} /$ ton $\cdot \mathrm{km}$ \\
\hline & Waste ion-exchange resin & & $1.21 \mathrm{E}-02$ & $\mathrm{kgCO}_{2 \mathrm{e}} / \mathrm{kg}$ \\
\hline & Wastewater & & $1.28 \mathrm{E}-03$ & $\mathrm{kgCO}_{2 \mathrm{e}} / \mathrm{kg}$ \\
\hline & PET resin & & $2.37 \mathrm{E}+00$ & $\mathrm{kgCO}_{2 \mathrm{e}} / \mathrm{kg}$ \\
\hline & Waste plastic (recycle) & & $1.86 \mathrm{E}-02$ & $\mathrm{kgCO}_{2 \mathrm{e}} / \mathrm{kg}$ \\
\hline & HDPE & & $2.03 E+00$ & $\mathrm{kgCO}_{2 \mathrm{e}} / \mathrm{kg}$ \\
\hline & Industrial water & & $1.02 \mathrm{E}-04$ & $\mathrm{kgCO}_{2 \mathrm{e}} / \mathrm{kg}$ \\
\hline & Flat board & & $8.72 \mathrm{E}-01$ & $\mathrm{kgCO}_{2 \mathrm{e}} / \mathrm{kg}$ \\
\hline & LDPE & & $1.86 \mathrm{E}+00$ & $\mathrm{kgCO}_{2 \mathrm{e}} / \mathrm{kg}$ \\
\hline \multirow{10}{*}{ Manufacturing } & Top water & \multirow{10}{*}{$\begin{array}{l}\text { National LCI DB } \\
\quad \text { (Korea) }\end{array}$} & $3.32 \mathrm{E}-04$ & $\mathrm{kgCO}_{2 \mathrm{e}} / \mathrm{kg}$ \\
\hline & Electricity & & $4.95 \mathrm{E}-01$ & $\mathrm{kgCO}_{2 \mathrm{e}} / \mathrm{kWh}$ \\
\hline & LNG-direct & & $2.21 \mathrm{E}+00$ & $\mathrm{kgCO}_{2 \mathrm{e}} / \mathrm{Nm}^{3}$ \\
\hline & LNG-indirect & & $5.95 \mathrm{E}-01$ & $\mathrm{kgCO}_{2 \mathrm{e}} / \mathrm{kg}$ \\
\hline & Wastewater & & $1.28 \mathrm{E}-03$ & $\mathrm{kgCO}_{2 \mathrm{e}} / \mathrm{kg}$ \\
\hline & Sludge (compost) & & $2.49 \mathrm{E}-01$ & $\mathrm{kgCO}_{2 \mathrm{e}} /$ ton $\cdot \mathrm{km}$ \\
\hline & Waste paper (recycle) & & $1.20 \mathrm{E}-01$ & $\mathrm{kgCO}_{2 \mathrm{e}} / \mathrm{kg}$ \\
\hline & Waste plastic (recycle) & & $1.86 \mathrm{E}-02$ & $\mathrm{kgCO}_{2 \mathrm{e}} / \mathrm{kg}$ \\
\hline & Waste plastic (incineration) & & $2.35 \mathrm{E}+00$ & $\mathrm{kgCO}_{2 \mathrm{e}} / \mathrm{kg}$ \\
\hline & Waste activated carbon (recycle) & & $1.36 \mathrm{E}-02$ & $\mathrm{kgCO}_{2 \mathrm{e}} / \mathrm{kg}$ \\
\hline \multirow{2}{*}{ Distribution } & Road transport (Metrepolitan) & \multirow{2}{*}{$\begin{array}{l}\text { National LCI DB } \\
\quad \text { (Korea) }\end{array}$} & $2.49 \mathrm{E}-01$ & $\mathrm{kgCO}_{2 \mathrm{e}} / \mathrm{ton} \cdot \mathrm{km}$ \\
\hline & Ship transport (Mokpo-Jeju) & & $8.37 \mathrm{E}-03$ & $\mathrm{kgCO}_{2 \mathrm{e}} /$ ton $\cdot \mathrm{km}$ \\
\hline \multirow{6}{*}{ End of life } & Waste plastic (recycle) & \multirow{6}{*}{$\begin{array}{l}\text { National LCI DB } \\
\quad \text { (Korea) }\end{array}$} & $1.86 \mathrm{E}-02$ & $\mathrm{kgCO}_{2 \mathrm{e}} / \mathrm{kg}$ \\
\hline & Waste plastic (incineration) & & $2.35 \mathrm{E}+00$ & $\mathrm{kgCO}_{2 \mathrm{e}} / \mathrm{kg}$ \\
\hline & Waste plastic (landfill) & & 7.98E-02 & $\mathrm{kgCO}_{2 \mathrm{e}} / \mathrm{kg}$ \\
\hline & Waste paper (recycle) & & $1.20 \mathrm{E}-01$ & $\mathrm{kgCO}_{2 \mathrm{e}} / \mathrm{kg}$ \\
\hline & Waste paper (incineration) & & $2.40 \mathrm{E}-02$ & $\mathrm{kgCO}_{2 \mathrm{e}} / \mathrm{kg}$ \\
\hline & Waste paper (landfill) & & $8.96 \mathrm{E}-01$ & $\mathrm{kgCO}_{2 \mathrm{e}} / \mathrm{kg}$ \\
\hline
\end{tabular}

질의 데이터 수집 기준에 대하여 누적중량 기여도 $95 \%$ cut-off 기준을 적용하고 있다. ${ }^{10)}$

일반적으로 국내에서 제조되는 탄산음료에는 $80 \%$ 이상의 물과 약 5 10\%의 설탕 시럽이 포함되어 있고, 그 외에 탄산가 스 및 기타 원료가 포함되어 있다. 본 연구 대상의 탄산음료 $500 \mathrm{~mL}$ 과 탄산음료 $1.5 \mathrm{~L}$ 에는 $87.4 \%$ 의 물과 $10.7 \%$ 의 설탕이 제품에 내용물로 포함되어 이를 근거로 하여 현장데이터를 수집하였다. 그 외에 탄산음료에 주입하는 탄산가스 및 향 성분 등의 기타 원료물질에 대해서는 환경부 방법론에 따른 누적중량 기여도 $95 \%$ cut-off 기준을 적용되어 현장데이터 수집 및 온실가스 배출량을 적용하지 않았다.
Table4와 Table5에서는 본 연구 대상의 탄산음료 $500 \mathrm{~mL}$, 탄산음료 $1.5 \mathrm{~L}$ 의 온실가스 배출량 산정 결과를 나타내었다. 탄산음료 $500 \mathrm{~mL}$ 의 전체 온실가스 배출량은 $186.03 \mathrm{gCO}_{2} / \mathrm{unit}$ 로 파악되었다. 제조 전단계의 온실가스 배출량은 $123.6 \mathrm{gCO}_{2} /$ unit으로 전체 온실가스 배출량의 $66.5 \%$ 로 가장 높았다. 원재 료인 설탕시럽(Sugar syrup) 제조에 6.7\%, PET병(Container) 제조에 $50.7 \%$, 마개(Stopper) 제조에 $4.6 \%, 2$ 차 포장재 (Shipment package) 제조에 $2.7 \%$ 그리고 원재료 및 포장재 수송(Input transtotation)에 3.2\%의 온실가스 배출량이 파악되 었다. 제조 단계의 온실가스 배출량은 $34.3 \mathrm{gCO}_{2} / \mathrm{unit}$ 으로 $18.4 \%$, 제품 운송단계(Output transportation)는 $14.2 \mathrm{gCO}_{2} / \mathrm{unit}$ 
Table 4. Calculation of greenhouse gas emissions and its contribution over product life cycle (a carbonated soft drink $500 \mathrm{~mL} / \mathrm{unit}$ ).

\begin{tabular}{|c|c|c|c|c|}
\hline Phase & Name & $\begin{array}{l}\mathrm{CO}_{2} \text { emissions } \\
\text { ( } \mathrm{gCO}_{2} \text { /unit) }\end{array}$ & $\begin{array}{c}\text { Contribution } \\
(\%)\end{array}$ & Remark \\
\hline \multirow{7}{*}{ Pre-manufacturing } & Sugar syrup & 12.5 & 6.7 & \\
\hline & \multirow{2}{*}{$\begin{array}{l}\text { Container } \\
\text { (PET bottle) }\end{array}$} & 66.8 & 35.9 & Preform process \\
\hline & & 27.5 & 14.8 & Blowing process \\
\hline & Stopper (Cap) & 8.6 & 4.6 & \\
\hline & Shipment package & 5.0 & 2.7 & \\
\hline & Input transportation & 3.2 & 1.7 & \\
\hline & Sub-total & 123.6 & 66.5 & \\
\hline Manufacturing & Production & 34.3 & 18.4 & \\
\hline Distribution & Output transportation & 14.2 & 7.6 & \\
\hline \multirow[t]{2}{*}{ End of life } & Waste disposal & 13.9 & 7.5 & \\
\hline & & 186.03 & 100.0 & \\
\hline
\end{tabular}

Table 5. Calculation of greenhouse gas emissions and its contribution over product life cycle (a carbonated soft drink 1.5 L/unit).

\begin{tabular}{|c|c|c|c|c|}
\hline Phase & Name & $\begin{array}{l}\mathrm{CO}_{2} \text { emissions } \\
\left.\text { ( } \mathrm{gCO}_{2} / \text { unit }\right)\end{array}$ & $\begin{array}{c}\text { Contribution } \\
(\%)\end{array}$ & Remark \\
\hline \multirow{7}{*}{ Pre-manufacturing } & Sugar syrup & 37.3 & 10.6 & \\
\hline & \multirow{2}{*}{$\begin{array}{l}\text { Container } \\
\text { (PET bottle) }\end{array}$} & 120.1 & 34.3 & Preform process \\
\hline & & 25.7 & 7.3 & Blowing process \\
\hline & Stopper (Cap) & 10.7 & 3.1 & \\
\hline & Shipment package & 9.8 & 2.8 & \\
\hline & Input transportation & 8.1 & 2.3 & \\
\hline & Sub-total & 211.8 & 60.5 & \\
\hline Manufacturing & Production & 93.2 & 26.6 & \\
\hline Distribution & Output transportation & 29.8 & 8.5 & \\
\hline \multirow[t]{2}{*}{ End of life } & Waste disposal & 15.4 & 4.4 & \\
\hline & & 350.2 & 100.0 & \\
\hline
\end{tabular}

으로 $7.6 \%$ 를, 마지막으로 최종 폐기단계는 $13.9 \mathrm{gCO}_{2} / \mathrm{unit}$ 으로 $7.5 \%$ 의 온실가스가 배출되는 것으로 파악되었다.

Table 5는 탄산음료 $1.5 \mathrm{~L}$ 의 온실가스 배출량 산정 결과를 정리하였다. 본 연구 대상의 탄산음료 $1.5 \mathrm{~L}$ 에도 $87.4 \%$ 의 물과 $10.7 \%$ 의 설탕으로 구성되어 이와 관련하여 현장데이터를 수 집하였으며, 탄산가스 등의 나머지 원료물질에 대해서는 탄산 음료 $500 \mathrm{~mL}$ 와 동일하게 누적질량 기여도 $95 \%$ cut-off 기준을 적용하였다. 탄산음료 $1.5 \mathrm{~L}$ 의 전체 온실가스 배출량은 350.2 $\mathrm{gCO}_{2}$ /unit로 분석되었다. 제조 전단계의 온실가스 배출량은 $211.8 \mathrm{gCO}_{2} / \mathrm{unit}$ 으로 전체 온실가스 배출량의 $60.5 \%$ 로 가장 높게 파악되었다. 원재료인 설탕시럽(Sugar syrup) 제조에 $10.6 \%$, PET병(Container) 제조에 $41.6 \%$, 마개(Stopper) 제조 에 $3.1 \%, 2$ 차 포장재(Shipment package) 제조에 $2.8 \%$ 그리고 원재료 및 포장재 수송(Input transtotation)에 $2.3 \%$ 의 온실 가스가 배출되었다. 제조 단계의 온실가스 배출량은 93.2 $\mathrm{gCO}_{2} /$ unit으로 $26.6 \%$, 제품 운송단계(Output transportation)의 온실가스 배출량은 $29.8 \mathrm{gCO}_{2} /$ unit으로 $8.5 \%$, 마지막으로 최
종 폐기단계(Waste disposal)는 $15.4 \mathrm{gCO}_{2} /$ unit으로 $4.4 \%$ 의 온 실가스가 배출되는 것으로 파악되었다.

Fig. 2는 탄산음료 $500 \mathrm{~mL}, 1.5 \mathrm{~L}$ 의 온실가스 배출량을 제품 $100 \mathrm{~mL}$ 를 기준 원단위를 산정하여 그래프로 비교하였다. 탄 산음료 $500 \mathrm{~mL}$ 의 온실가스 배출 원단위는 $37.2 \mathrm{gCO}_{2} / 100 \mathrm{~mL}$ 으로 조사되었으나 탄산음료 $1.5 \mathrm{~L}$ 는 $23.3 \mathrm{gCO}_{2} / 100 \mathrm{~mL}$ 으로, 온실가스 배출 원단위 비교결과 탄산음료 $1.5 \mathrm{~L}$ 제품이 탄산음 료 $500 \mathrm{~mL}$ 에 비해 온실가스 배출 원단위가 낮은 것으로 확인 되었다.

제조 전단계에서 탄산음료 $500 \mathrm{~mL}$ 의 온실가스 배출 원단위 는 $24.7 \mathrm{gCO}_{2} / 100 \mathrm{~mL}$ 이나 탄산음료 $1.5 \mathrm{~L}$ 는 $14.1 \mathrm{gCO}_{2} / 100$ $\mathrm{mL}$ 로 조사되어, 탄산음료 $500 \mathrm{~mL}$ 의 온실가스 원단위가 탄산 음료 $1.5 \mathrm{~L}$ 에 약 1.8 배 높은 것으로 확인되었다. 특히 PET병 제조에 따른 온실가스 배출량은 제조 전단계의 69 76\%로 가 장 높은 비율을 점유하는데, 온실가스 배출 원단위가 PET병 $500 \mathrm{~mL}$ 는 $18.9 \mathrm{gCO}_{2} / 100 \mathrm{~mL}$ 이나 PET병 $1.5 \mathrm{~L}$ 는 $9.7 \mathrm{gCO}_{2} / 100$ $\mathrm{mL}$ 로 약 1.9 배로 확인되어 제조 전단계에서의 온실가스 배출 


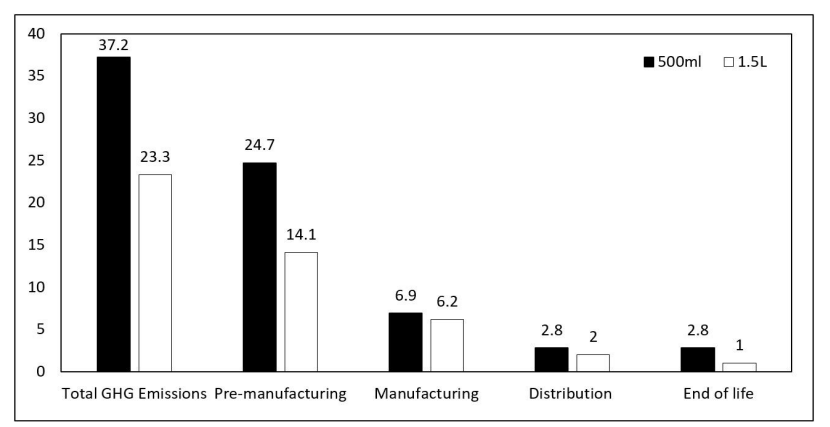

Fig. 2. The comparision of the toal greenhouse gas emissions and its units per $100 \mathrm{~mL}$ of carbonated soft drinks.

원단위와 유사한 트렌드를 나타냄을 확인할 수 있다.

제조 단계는 탄산음료 $500 \mathrm{~mL}$ 의 온실가스 배출 원단위는 $6.9 \mathrm{gCO}_{2} / 100 \mathrm{~mL}$ 이고 탄산음료 $1.5 \mathrm{~L}$ 는 $6.2 \mathrm{gCO}_{2} / 100 \mathrm{~mL}$ 로, 탄산음료 $500 \mathrm{~mL}$ 와 탄산음료 $1.5 \mathrm{~L}$ 의 제조 원단위 차이가 약 1.2 배 수준으로 제품 용량에 따른 제조 단계에서의 온실가 스 배출 원단위의 유의미한 차이는 확인되지 않았다.

제품 운송단계(Output transportation)에서 탄산음료 $500 \mathrm{~mL}$ 의 온실가스 배출 원단위는 $2.8 \mathrm{gCO}_{2} / 100 \mathrm{~mL}$ 으로 분석되었 고 탄산음료 $1.5 \mathrm{~L}$ 는 $2.0 \mathrm{gCO}_{2} / 100 \mathrm{~mL}$ 으로 확인되어 탄산음 료 $500 \mathrm{~mL}$ 의 제품 운송단계의 온실가스 원단위가 높게 나타 났다.

최종 폐기단계(Waste disposal)에서 탄산음료 $500 \mathrm{~mL}$ 의 온 실가스 배출 원단위는 $2.8 \mathrm{gCO}_{2} / 100 \mathrm{~mL}$, 탄산음료 $1.5 \mathrm{~L}$ 는 $1.0 \mathrm{gCO}_{2} / 100 \mathrm{~mL}$ 로 조사되었다. 최종 폐기단계에서는 단위 제품 부피에 투입되는 포장재 원료가 탄산음료 $500 \mathrm{~mL}$ 가 탄 산음료 $1.5 \mathrm{~L}$ 에 비교하여 많이 사용되기에, 폐기단계의 온실 가스 배출 원단위가 제조 전단계와 유사한 경향으로 조사됨을 알 수 있다.

\section{2. 민감도 분석}

전과정평가에서는 대상 연구의 신뢰도 제고를 위해 현장데 이터 및 적용된 가정에 대한 불확실성을 평가하는데 이를 민 감도 분석(Sensitivity analysis)이라고 한다. 민감도 분석에서 는 가정 및 데이터를 일정범위 변화시켰을 때 그 결과의 영향 을 분석하며 민감도는 변화분율 또는 결과의 절대적 편차로 표현될 수 있다. 일반적으로 결과가 $10 \%$ 이상 차이가 날 경우 에는 적용된 데이터 및 가정에 대한 적용을 신중하고 고려해 야 한다. Heo 외(2017)는 재생 플라스틱을 휴대폰 충전기 적용 한 경우에 대한 전과정평가 기법을 적용한 연구결과에 대해 민감도 분석을 실시하였으며, 그 결과 총 12 개 항목에서 민간 도가 $10 \%$ 미만으로 도출되어 연구결과를 신뢰할 수 있음을 보고하였다. ${ }^{4}$

본 연구에서도 신뢰도 제고를 위해 탄산음료 $500 \mathrm{~mL}$, 탄산 음료 $1.5 \mathrm{~L}$ 에 대한 민감도 분석을 실시하였다. 본 연구 및 사례연구를 통해서 확인한 결과, 탄산음료는 포장재 제조과정
에서의 플라스틱 원료의 사용과 폐기단계에서의 플라스틱 재 질의 포장재 재활용율에 따른 데이터 변동이 큰 것으로 확인 되었다. 참고로 우리나라는 재활용 플라스틱의 식품용기에 사용하는 것에 대한 유해성 이슈가 정리되지 않아 음료용기에 재활용 플라스틱 원료를 사용하지 않고 있다. 또한 탄산음료 는 제품 특성상 탄산을 주입하는데 병 내부가 탄산 내압을 견딜 수 있도록 PET병을 설계해야 한다. 그러나 아직 재활용 플라스틱을 PET병에 신재와 혼합하여 제조할 경우의 품질 이슈도 확인이 필요한 실정이다.

따라서 본 연구의 민감도 분석은 재활용 플라스틱의 신재와 일부 혼합하는 것을 가정하여 다음의 3 가지 항목에 대해 실시 하였다

첫째, 제조 전단계에 해당되는 PET병 제조공정에서 PET병 원료로 $100 \%$ 신재 $\mathrm{PET}$ 를 사용한 것과 $20 \%$ 의 재활용 $\mathrm{PET}$ 를 혼합한 경우의 온실가스 배출량을 비교하였다. 둘째, 제조 전 단계에 해당되는 마개 제조공정에서 마개 원료로 $100 \%$ 신재 $\mathrm{HEPE}$ 를 사용한 것과 $20 \%$ 의 재활용 $\mathrm{HDPE}$ 를 혼합한 경우의 온실가스 배출량을 비교하였다. 셋째, 최종 페기단계에서 본 연구에서 적용한 폐플라스틱 재활용비율 $80 \%$ 적용한 것과 기존 재활용비율을 $10 \%$ 향상시킨 폐플라스틱 재활용비율 $90 \%$ 를 적용한 경우의 온실가스 배출량을 비교하였고 그 결과 는 Table 6과 같다.

PET병 제조공정에서 PET병 원료로 $100 \%$ 신재 PET를 사용 한 것과 $20 \%$ 의 재활용 $\mathrm{PET}$ 를 혼합한 경우의 온실가스 배출량 의 민감도 분석 결과, 탄산음료 $500 \mathrm{~mL}$ 는 $6.2 \%$ 를 탄산음료 $1.5 \mathrm{~L}$ 는 $6.1 \%$ 의 변화를 유발하였다. 마개 제조공정에서 마개 원료로 $100 \%$ 신재 HEPE를 사용한 것과 $20 \%$ 의 재활용 $\mathrm{HDPE}$ 를 혼합한 경우의 온실가스 배출량의 민감도 분석 결과, 탄산 음료 $500 \mathrm{~mL}$ 는 $0.5 \%$ 를 탄산음료 $1.5 \mathrm{~L}$ 는 $0.3 \%$ 의 변화를 유발 하였다. 최종 페기단계에서 본 연구에서 적용한 폐플라스틱 재활용비율 $80 \%$ 적용한 것과 기존 재활용비율을 $10 \%$ 향상시 킨 폐플라스틱 재활용비율 $90 \%$ 를 적용한 경우의 온실가스 배출량의 민감도 분석 결과, 탄산음료 $500 \mathrm{~mL}$ 는 $2.8 \%$ 를 탄산 음료 $1.5 \mathrm{~L}$ 는 $1.9 \%$ 로 조사되었다. 결과적으로 위의 연구결과 와 같이 온실가스 배출량 변화량은 모든 분석 대상항목에 대 해 $7 \%$ 미만으로 연구결과에 미치는 영향이 크지 않은 것으로 파악되었다.

\section{4. 결론}

본 연구에서는 탄산음료 $500 \mathrm{~mL}$ 와 $1.5 \mathrm{~L} \mathrm{PET병} \mathrm{제품의}$ 온실가스 배출량에 대해 전과정평가 기법을 사용하여 산정하 였다. 탄산음료 $500 \mathrm{~mL}$ 의 온실가스 배출량 산정 결과 전체 온실가스 배출량은 $186.03 \mathrm{gCO}_{2} /$ unit로 조사되었다. 제조 전단 계의 온실가스 배출량은 $123.6 \mathrm{gCO}_{2} / \mathrm{unit}$ 으로 전체 온실가스 배출량의 $66.5 \%$ 로 가장 높고, 제조 단계는 $34.3 \mathrm{gCO}_{2} / \mathrm{unit}$ 으로 
Table 6. Sensitivity analysis results for case study ( $\left.\mathrm{gCO}_{2} / \mathrm{unit}\right)$.

\begin{tabular}{|c|c|c|c|c|c|c|c|c|}
\hline \multirow{3}{*}{ Scenario } & \multicolumn{4}{|c|}{ Case } & \multirow{2}{*}{\multicolumn{2}{|c|}{$\begin{array}{c}\text { Deviation } \\
(\mathrm{A}-\mathrm{B})\end{array}$}} & \multirow{2}{*}{\multicolumn{2}{|c|}{$\begin{array}{c}\text { Sensitivity } \\
(\mathrm{A}-\mathrm{B}) / \mathrm{A}\end{array}$}} \\
\hline & \multicolumn{2}{|c|}{$\begin{array}{c}\text { This study } \\
\text { (A) }\end{array}$} & \multicolumn{2}{|c|}{$\begin{array}{l}\text { Case study } \\
\text { (B) }\end{array}$} & & & & \\
\hline & $500 \mathrm{~mL}$ & $1.5 \mathrm{~L}$ & $500 \mathrm{~mL}$ & $1.5 \mathrm{~L}$ & $500 \mathrm{~mL}$ & $1.5 \mathrm{~L}$ & $500 \mathrm{~mL}$ & $1.5 \mathrm{~L}$ \\
\hline $\begin{array}{l}\text { Recycled PET } \\
(20 \%)\end{array}$ & 186.03 & 350.21 & 174.40 & 328.96 & 11.63 & 21.24 & $6.2 \%$ & $6.1 \%$ \\
\hline $\begin{array}{l}\text { Recycled HDPE } \\
(20 \%)\end{array}$ & 186.03 & 350.21 & 185.09 & 349.26 & 0.94 & 0.94 & $0.5 \%$ & $0.3 \%$ \\
\hline $\begin{array}{c}\text { End of life } \\
\text { (Improved recycling rate 10\%) }\end{array}$ & 186.03 & 350.21 & 180.78 & 343.63 & 5.25 & 6.57 & $2.8 \%$ & $1.9 \%$ \\
\hline
\end{tabular}

$18.4 \%$, 제품 운송단계는 $14.2 \mathrm{gCO}_{2} /$ unit으로 $7.6 \%$ 를 최종 폐 기단계는 $13.9 \mathrm{gCO}_{2}$ /unit으로 $7.5 \%$ 로 나타났다. 탄산음료 1.5 $\mathrm{L}$ 의 온실가스 배출량은 $350.2 \mathrm{gCO}_{2} / \mathrm{unit}$ 로 산출되었다. 제조 전단계의 온실가스 배출량은 $211.8 \mathrm{gCO}_{2} / \mathrm{unit}$ 으로 전체 온실 가스 배출량의 $60.5 \%$ 로 탄산음료 $500 \mathrm{~mL}$ 와 동일하게 가장 높았고, 제조 단계는 $93.2 \mathrm{gCO}_{2} /$ unit으로 $26.6 \%$, 제품 운송단 계는 $29.8 \mathrm{gCO}_{2} /$ unit으로 $8.5 \%$ 를 최종 폐기단계는 15.4 $\mathrm{gCO}_{2} / \mathrm{unit}$ 으로 $4.4 \%$ 로 분석되었다. 이와 같이 탄산음료 온실 가스 배출량의 60.5 66.5\%는 포장재를 주로 포함하는 제조 전단계에서 발생되는 것으로 조사되었다. 이러한 연구결과를 토대로 하여 탄산음료의 온실가스 배출량을 저감하기 위해서 는 플라스틱 포장재 경량화 또는 플라스틱 포장재 원료로 재활용 플라스틱을 사용하여 PET병 등의 포장재를 제조하는 것이 탄산음료 제품의 온실가스 배출을 줄이는데 필요함을 확인하였다. 이를 위해서는 국내 재활용 플라스틱의 식품용 기 적용시 식약처 및 환경부와 같은 정부 기관의 유해성 문제 에 대한 제도정비도 필요하다. 또한 본 연구와 같이 소비재 제품의 온실가스 배출량 정보공개 및 인증은 산업계 온실가 스 감축 및 저탄소 소비자 문화 확대에도 기여할 것으로 사료 된다.

\section{References}

1. Korea Meteorological Administration, Korean Climate Change Assessment Report 2020(2020).

2. Ministry of Environment, The Strategy to Achieve National Emission Targets 2030 to be Renewed(2018).

3. Korea Environmental Industry \& Technology Institute, http://www.edp.or.kr/(2020).

4. Y. Heo, D. Bae, C. Oh, Y. Suh, K. Lee, Life cycle assessment of mobile phone charger containing recycled plastics, J. Korean Soc. Environ. Eng., 39(12), 698-705(2017).

5. I.-H. Kwak, Y.-W. Hwang, K.-H. Park, J.-H. Park, S.-Y. Seol, H.-J. Shin, E.-H. Yang, G.-S. Min, Environmental evaluation for the remanufacturing of rental product using the LCA methodology, J. Korean Soc. Environ. Eng., 38(11), 611-617(2016).
6. J. Kim, S. Jeon, J. Song, G. Choi, A study on particulate matter footprint calculation on transportation modes, J. Korean Soc. Environ. Eng., 42(1), 1-9(2020).

7. Korea Agro-Fisheries \& Food Trade Coporation, The Current Status of 2019 Processed Food Segment Market (Beverages)(2019).

8. J. Pasqualino, M. Meneses, F. Castells, The carbon footprint and energy consumption of beverage packaging selection and disposal, J. Food Eng., 103(4), 357-365(2011).

9. D. Amienyo, H. Gujba, H. Stichnothe, A. Azapagic, Life cycle environmental impacts of carbonated soft drinks, Int. J. Life Cycle Assess., 18, 77-92(2013).

10. Korea Environmental Industry \& Technology Institute, Environment Product Declaration Certification Crieteria(2017).

11. Future Market Insights, 2019 Analysis and Review of Beverage Packaging Market by Application - Alcoholic Drinks, Non-Alcoholic for 2019-2027(2020).

\section{Declaration of Competing Interest}

The authors declare that they have no known competing financial interests or personal relationships that could have appeared to influence the work reported in this paper.

\section{Authors and Contribution Statement}

\section{Jongsek Kim}

Department of Environmental Engineering, University of Seoul, Ph.D. Course Student, ORCID (0) 0000-0001-5015-2852: Conceptualization, Methodology, Writing - original draft.

\section{Noh Hyun Lim}

Institute of Global Sustainability Certificate (IGSC), CEO, ORCID( 0000-0001-8822-8621: Methodology, Data analysis.

\section{Yoonmi Shin}

Department of Environmental Engineering, University of Seoul, Ph.D. Course Student, ORCID (1) 0000-0003-1874-502X: Validation. 


\section{Kyungwook Park}

Department of Environmental Engineering, University of Seoul, Ph.D. Course Student, ORCID (1) 0000-0002-7988-6267: Visualization.

\section{Ihn Sup Han}

Department of Environmental Engineering, University of Seoul, Ph.D., Professor, ORCiD \0000-0002-6826-2627: Conceptualization, Resources. 